\title{
IDENTIFIKASI POTENSI JABON MERAH (ANTHOCEPHALUS MARCOPHYLLUS) DI KECAMATAN BUA KABUPATEN LUWU
}

\author{
(Identifying the Potential of Jabon Merah (Anthocephalus marcophyllus) in Bua Subdistrict \\ Luwu District)
}

\author{
Dhiki Efendi ${ }^{1}$, Andi Rosdayanti ${ }^{2}$, dan Afandi Ahmad ${ }^{2}$ \\ ${ }^{1}$ Mahasiswa Program Studi Kehutanan Fakultas Kehutanan,Universitas Andi Djemma Palopo \\ ${ }^{2}$ Dosen Fakultas Kehutanan Universitas Andi Djemma Palopo \\ (DhikiEfendy24@gmail.com)
}

\begin{abstract}
Community forest is one model of natural resource managements based on community initiatives. The development of community forests is directed at restoring land productivity. Scarcity of industrial wood raw materials requires fast-growing commercial wood, jabon merah is a fast-growing plant. Potential of jabon merah at Bua District has not been known certainly. Inventory studies contain descriptions of forested areas and potential assessments. Bua sub-district is one of the sub-districts producing jabon merah wood that comes from community forests. This research was conducted from August to September 2019 with the aim to find out how much the potential for jabon merah and the distribution of jabon merah are in Bua sub-district. This research was conducted by quantitative description method. the results obtained by an inventory of the potential of jabon merah in Bua sub-district are $5,127 \mathrm{~m}^{3}$. Volume of jabon merah for each diameter class is $0.99 \mathrm{~m}^{3}$ for the diameter class of 5-10.99 $\mathrm{cm}, 277.60 \mathrm{~m}^{3}$ for the diameter class of $11-19.99 \mathrm{~cm}, 338.20 \mathrm{~m}^{3}$ for the diameter class of 20$29.99 \mathrm{~cm}$, and $122.15 \mathrm{~m}^{3}$ for the widest class located in the village of Tiromanda with 11 stands of jabon merah stands, witharea of 5.3 ha.The lowest and lowest distribution is located in Lare-Lare village, only 1 area of jabon merah stands, with an area of $0.8 \mathrm{ha}$.
\end{abstract}

Keywords: Forest of the people, Potential, Distribution, Jabon Merah.

\begin{abstract}
ABSTRAK
Hutan rakyat merupakan salah satu model pengelolaan sumber daya alam berdasarkan inisiatif masyarakat. Pembangunan hutan rakyat diarahkan untuk mengembalikan produktifitas lahan. Kelangkaan bahan baku kayu industri membutuhkan kayu komersil yang cepat tumbuh, Jabon merah merupakan tumbuhan cepat tumbuh. Besar potensi Jabon merah belum diketahui secara pasti. Ilmu inventarisasi berisi deskripsi areal berhutan dan penaksiran potensi. Kecamatan Bua adalah salah satu kecamatan penghasil kayu Jabon merah yang berasal dari hutan rakyat. Penelitian ini dilakukan pada bulan Agustus sampai dengan September 2019 dengan tujuan untuk mengetahui berapa besar potensi Jabon merah, dan sebaran Jabon merah di Kecamatan Bua. Penelitian ini di lakukan dengan metode deskripsi kuantitatif. Hasil yang diperoleh dari inventarisasi potensi Jabon merah di Kecamatan Bua yaitu $5.127 \mathrm{~m}^{3}$. Volume Jabon merah untuk setiap kelas diameter diperoleh sebesar $0,99 \mathrm{~m}^{3}$ untuk kelas diameter 5$10,99 \mathrm{~cm}, 277,60 \mathrm{~m}^{3}$ untuk kelas diameter $11-19,99 \mathrm{~cm}, 338,20 \mathrm{~m}^{3}$ untuk kelas diameter 20$29,99 \mathrm{~cm}$, dan 122,15 $\mathrm{m}^{3}$ untuk kelas diameter 30-39,99 cm. Sebaran Jabon merah di Kecamatan Bua, sebaran tertinggi dan terluas terletak di Desa Tiromanda sebanyak 11 areal tegakan Jabon merah, dengan luasan sebesar 5,3 ha. Sebaran terendah dan terkecil terletak di Desa Lare-Lare hanya 1 areal tegakan Jabon merah, dengan luasan sebesar 0,8 ha.
\end{abstract}

Kata Kunci: Hutan Rakyat, Potensi, Sebaran, Jabon Merah. 


\section{PENDAHULUAN}

Hutan merupakan sumber daya alam yang banyak berpengaruh terhadap kehidupan manusia. Manusia melakukan interaksi dengan hutan untuk memenuhi kebutuhan hidupnya. Hutan adalah suatu kesatuan ekosistem berupa hamparan lahan berisi sumber daya alam hayati yang didominasi pepohonan dan persekutuan alam lingkungannya yang satu dengan yang lainnya tidak dapat dipisahkan (UU RI No 41 tahun 1999 tentang kehutanan). Sehingga hutan merupakan sumber daya alam yang banyak memberikan pengaruh secara langsung maupun tidak langsung terhadap kehidupan manusia.

Hutan rakyat merupakan salah satu model pengelolaan sumberdaya alam yang berdasarkan inisiatif masyarakat, pada umumnya di Indonesia Hutan Rakyat dikembangkan pada lahan masyarakat. Pembangunan hutan rakyat diarahkan untuk mengembalikan produktivitas lahan kritis, konservasi lahan, perlindungan hutan, dan pengentasan kemiskinan melalui upaya pemberdayaan masyarakat di dalam dan di sekitar kawasan. Kemampuan hutan rakyat sebagai alternatif pemenuhan kebutuhan bahan baku menjadi daya tarik tersendiri bagi industri perkayuan (Awang et al. 2007).

Saat ini keberadaan industri kayu mengalami masalah yang serius mengenai kebutuhan bahan baku kayu. Kebutuhan akan kayu komersil di Indonesia semakin meningkat sedangkan potensi hutan di Indonesia semakin berkurang baik dari luas hutan produksi maupun dari sisi kualitas kayu yang dihasilkan (Wardhani, 2011). Keadaan ini mendorong pemerintah dan instansi terkait mengadakan pembangunan HTI (hutan tanaman industri). Semakin langkanya produksi hutan alam. HTI menjadi tumpuan produksi hasil hutan masa depan.
Kelangkaan bahan baku kayu dapat diatasi dengan mencari jenis tanaman yang berkualitas dan memiliki riap tumbuh yang cepat (fast growing species) (Cahyono et al. 2012). Penentuan jenis pohon jangan sampai salah, jenis tanaman yang dikembangkan dalam program HTI tidak banyak, umumnya berasal dari fast growing species (Warman, 2014). Salah satu tanaman yang memiliki pertumbuhan yang sangat cepat seperti Jabon merah (Cahyono et al. 2012). Jabon merah adalah salah satu jenis unggulan yang dapat dikembangkan melalui hutan tanaman industri maupunhutan rakyat.

Jabon merah (Anthocephalus marcophyllus) merupakan jenis pohon industry yang cepat tumbuh dari famili (Rubiaceae) memiliki banyak kegunaan. Karena tergolong tumbuhan yang cepat tumbuh, maka Jabon merah memiliki daur lebih pendek, sehingga menguntungkan dari segi produksi yang tinggi dalam waktu yang singkat.Jabon merah juga tergolong jenis pohon cahaya (light-demanding) dan cepat tumbuh pada usia yang masih muda.Di alam, pohon Jabon merah dapat tumbuh tinggi mencapai $45 \mathrm{~m}$ dengan tinggi bebas cabang $30 \mathrm{~m}$, serta dapat mencapai diameter $160 \mathrm{~cm}$. Pohon Jabon merah memiliki batang lurus dan silindris, penanamannya mudah dikerjakan, dan mudah mendapatkan benih dalam jumlah yang banyak serta tidak ada hambatan dalam pengadaan bibit secara besar-besaran (Martawidjaya et al.2005).

Jenis jabon merah telah diusahakan dan dikelola secara tradisional. Hanya saja berapa besar potensi yang disumbangkan dari tanaman Jabon merah belum diketahui secara pasti. Data potensi kayu sangat diperlukan untuk memberikan informasi ketersediaan bahan baku kayu kepada industri yang mana pasokan bahan baku kayu tidak cukup memenuhi kebutuhan apalagi hanya mengandalkan dari hutan alam. Apabila informasi potensi sudah diketahui, Pemerintah dapat mengambil kebijakan- 
kebijakan terkait pengembangan tanaman cepat tumbuh khususnya Jabon merah. Penelitian mengenai potensi Jabon Merah perlu dilakukan (Tarigan. 2009).

Inventarisasi

sumber

daya

hutanmerupakan hal sangat penting dalam pengelolaan hutan.Ilmu inventarisasi berisi deskripsi areal berhutan serta kepemilikannya, penaksiran potensi, penaksiran volume pohon yang masih berdiri, luas bidang dasar, diameter pohon, panaksiran riap, dan pengeluaran hasil (Hush, 1987 dalam Eventi, 2010). Inventarisasi sangat dibutuhkan apabila ingin mencapai pengelolaan dan pengurusan hutan secara lestari sustainabel forest management (Safitri, E. 2009).

Potensi kayu Jabon merah (Anthocephalusmarcophyllus) sebagai bahan baku pulp, kayu lapis, dan kertas di dukung dengan panjang seratnya melebihi panjang serat kayu akasia (Acasia mangium) dan kayu eukaliptus ( Eucalyptus) yang secara industri sudah digunakan sebagai bahan baku pulp, kayu lapis, dan kertas (Tarigan, 2009). Kecamatan Bua adalah salah satu kecamatan penghasil kayu Jabon merah(Anthocephalus marcophyllus) yang berasal dari Hutan Rakyat. Kecamatan Bua berjarak sekitar \pm 4 Km dari Pt. Saemporna Kayu, sehingga hasil Hutan Rakyat di Kecamatan Bua adalah salah satu penyuplai bahan baku pada perusahaan tersebut (Bukhari, 2015). Berdasarkan latar belakang diatas, peneliti tertarik melakukan penelitian : "Identifikasi Potensi Jabon Merah (Anthocephalus marcophyllus) Di Kecamatan Bua Kabupaten Luwu". Tujuan dari penelitian ini adalah untuk mengetahui seberapa besar potensi Jabon merah (Anthocephalus marcophyllus) di Kecamatan Bua Kabupaten Luwu. Selain itu, untuk mengetahui potensi sebaran Jabon merah (Anthocephalus marcophyllus) di Kecamatan Bua Kabupaten Luwu .

\section{METODE PENELITIAN}

Penelitian ini dilaksanakan pada bulan Agustus sampai dengan September 2019. Lokasi Penelitian terletak di kawasan hutan rakyat setiap Desa di Kecamatan Bua Kabupaten Luwu.Metode penelitian menggunakan metode deskripsi kuantitatif. Metode deskripsi kuantitatif di lakukan melalui penelitian lapangan (survey langsung ke lapangan).

Jenis data yang digunakan dalam penelitian ini antara lain : (1)Data primer berupa keliling pohon, tinggi pohon, volume pohon, luas bidang dasar, titik koordinat setiap kawasan yang berisi jabon di setiap Desa di Kecamatan Bua. (2) Data sekunder meliputi kondisi geografis lokasi penelitian, serta datadata lain yang berkaitan dengan penelitian yang bersumber dari pustaka ataupun instansi terkait. Tehnik pengambilan sampel dalam penelitian ini menggunakan tehnik purposive sampling. Purposive sampling adalah tehnik untuk menentukan sampel penelitian dengan beberapa pertimbangan tertentu yang bertujuan agar data yang diperoleh nantinya biar lebih representatif (Sugiyono, 2010). Pengambilan sampel dengan purposive dengan mempertimbangkan areal Jabon merah yang terpisah-pisah. Kecamatan Bua terdiri dari 15 desa, yang dapat diamati atau dijadikan sebagai objek penelitian hanya 12 desa. Dari 12 desa, 4 desa yang diambil sebagai sampel dengan pertimbangan areal Jabon merah yang lebih luas dibandingkan desa lainnya, untuk memudahkan pengambilan sampel sehingga dapat memperoleh data potensi Jabon merah. Plot yang di buat berukuran persegi empat dengan luas plot ukur $20 \mathrm{~m}$ x $20 \mathrm{~m}$ yang terletak secara disengaja.Penentuan lokasi plot contoh ditentukan disetiap luas lahan areal Jabon merah di 4 desa sampel, jumlah plot disesuaikan dengan luas lahan areal Jabon merah yang ada dilapangan. Lalu dihitung 
jumlah pohon dalam plot dan diukur keliling batang setinggi dada dan tinggi bebas cabang.

Data dikumpulkan dengan metode survei. Untuk mengetahui kondisi potensi dan sebaran Jabon merah di 4 desa sampel di Kecamatan Bua dilakukan pengamatan terhadap potensi pohon Jabon merah yang ada di dalam plot, seperti: (1) Data potensi Jabon merah yaitu keliling pohon, diameter pohon, tinggi bebas cabang, dan potensi Jabon Merah di 4desa sampel di Kecamatan Bua Kabupaten Luwu.

(2) Data Sebaran Jabon merah yaitu pengambilan titik koordinat di setiap kawasan yang berisi tanaman Jabon merah di setiap desa di Kecamatan Bua. Analisi data yang dihasilkan akan dilakukananalisis data dengan menggunakan persamaan sebagai berikut:

1. Diameter Pohon

Rumus diameter pohon yaitu sebagai berikut (Simon. 2007):

$$
\mathrm{D}=\mathrm{K} / \pi
$$

Keterangan:

$\mathrm{d}=$ diameter pohon setinggi dada $(\mathrm{cm})$

$\mathrm{k}=$ keliling batang pohon

$\pi=3,14$

\section{Luas Bidang Dasar Pohon}

Rumus luas bidang dasar pohon yaitu sebagai berikut (Widayantiet al. 2005) :

$$
\text { LBDS }=1 / 4 \cdot \pi \cdot d^{2}
$$

Keterangan :

LBDS = luas bidang dasar pohon $\left(\mathrm{m}^{2}\right)$,

$\pi=3,14$,

$\mathrm{d}=$ diameter pohon setinggi dada $(\mathrm{m})$,

\section{Tinggi Pohon}

Tinggi pohon adalah jarak terpendek antara suatu titik dengan titik proyeksinya pada bidang datar atau bidang horizontal (Simon. 2007).

$$
\mathrm{TP}=\mathrm{Tbc}-\mathrm{Tp}
$$

Keterangan :

$\mathrm{TP} \quad=$ Tinggi Pohon

Tbc = Tinggi Bebas Cabang
Tp = Tinggi Pangkal

4. Volume Pohon

Volume total suatu batang, dapat dihitung dengan menggunakan rumus berikiut (Widayantiet al. 2005) :

$\mathrm{V}=\mathrm{LBDS} \times \mathrm{t} \times \mathrm{f}$

Keterangan :

$\mathrm{V} \quad=$ volume pohon $\left(\mathrm{m}^{3}\right)$

LBDS $=$ Luas bidang dasar $\left(\mathrm{m}^{2}\right)$

$\mathrm{T}=$ tinggi bebas cabang $(\mathrm{m})$

$\mathrm{F} \quad=$ angka bentuk $(0,8)$

5. Pendugaan Potensi Per Hektar

Potensi per hektar dapat di hitung menggunakan rumus sebagai berikut (Malamassam, 2009) :

$\mathrm{V} /$ plot $=\sum \mathrm{Vi}$

$\mathrm{V} \mathrm{rata}{ }^{2} /$ plot $=\sum \mathrm{Vi} / \mathrm{n}$

$\mathrm{V} \mathrm{rata} / \mathrm{ha}=\underline{\text { Volume rata-rata per plot }}$

Simpangan baku $S=\sqrt{ } S^{2}$

Galat baku $S V=\frac{S}{\sqrt{n}} \sqrt{\frac{\left(1-{ }^{n}\right.}{N}}$

Sampling error $=\mathrm{t}_{\boldsymbol{\alpha}} / \mathbf{2} . S V$

keterangan :

$\sum \mathrm{Vi}=$ volume pohon $\left(\mathrm{m}^{3}\right)$

$\mathrm{n} \quad=$ Plot

$\mathrm{N}=$ Luas plot 0,04 ha $\left(400 \mathrm{~m}^{2}\right)$

Nilai 2,62 adalah $\mathrm{t}_{\boldsymbol{\alpha}} / 2 . S_{V}$ untuk taraf kepercayaan $95 \%$

6. Potensi

Potensi keseluruhan Jabon merah di Kecamatan Bua, dapat dihitung dengan menggunakan rumus berikut :

Potensi $=$ V/ha $\mathrm{x}$ Luas Areal Jabon Merah

7. Pembuatan Peta Sebaran Potensi Jabon Merah

Analisis data sebaran potensi Jabon merah, yaitu pembuatan peta sebaran potensi Jabon merahdi Kecamatan Bua dengan data titik koordinat yang diambil dengan GPS. Proses 
pengambilan data titik koordinat yang diambil dari lapangan adalah sebagai berikut : (1) Pengambilan titik koordinat dengan menggunakan alat GPS, data titik koordinat diambil dari 12 desa yang berisi tanaman Jabon merah di Kecamatan Bua. (2) Pengolahan data dengan memasukkan data titik koordinat yang diambil menggunakan GPS ke laptop dengan menggunakan aplikasi berbasis Sistem Informasi Geografis (GIS). (3) Penyajian peta sebaran Jabon merah (Anthocephalus marcophyllus) di Kecamatan Bua Kabupaten Luwu.

\section{HASIL DAN PEMBAHASAN}

\section{Potensi Jabon Merah}

Hasil penelitian potensi Jabon merah (Anthocephalus marcophyllus) di Kecamatan Bua ditemukan diameter tegakan berkisaran antara $5 \mathrm{~cm}-39,99 \mathrm{~cm}$. Berdasarkan rentang diameter tersebut, kemudian dibagi kedalam kelas diameter yaitu 5-10,99 cm, 11-19,99 cm, 20-29,99 cm, dan 30-39,99 cm. Adapun kelas diameter yang didapatkan dari hasil inventarisasi areal tegakan Jabon merah di Kecamatan Bua diperoleh masing-masing jumlah pohon setiap kelas diameter dan volume setiap kelas diameter seperti gambar 1 .

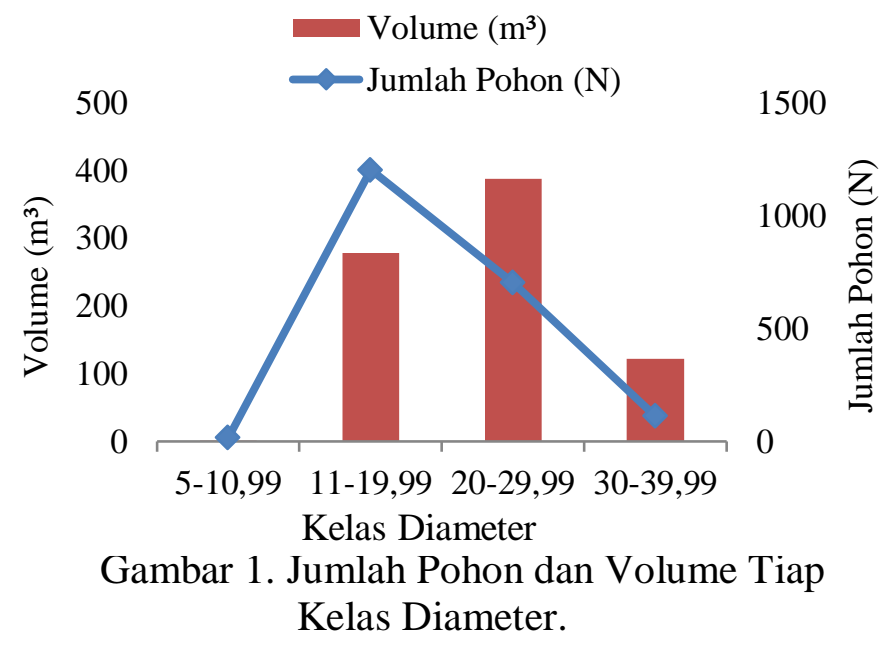

Gambar 1. menjelaskan bahwa hasil inventarisasi areal tegakan jabon merah di Kecamatan Bua menghasilkan volume terendah sebesar $0,99 \mathrm{~m}^{3}$ untuk tingkat kelas diameter 5-10,99 $\mathrm{cm}$ dengan jumlah pohon sebanyak 16 pohon, sedangkan volume tertinggi sebesar $388,20 \mathrm{~m}^{3}$ untuk kelas diameter 30-39,99 cm dengan jumlah pohon yang didapatkan sebanyak 703 pohon. Menurut Ismailet al. (2016) mengenai volume rata-rata per hektar di setiap kelas diameter di Kecamatan Majalengka secara umum ada pada kelas diameter 10-19 cm, 20-29 cm, 30$39 \mathrm{~cm}$ dan 40-49 $\mathrm{cm}$, volume rata-rata per hektar sebesar $92,03 \mathrm{~m}^{3} / \mathrm{ha}$, dengan jumlah pohon sebesar 300 pohon.

Tabel 1. Inventarisasi Jabon Merah di Areal Hutan Rakyat di Kecamatan Bua.

\begin{tabular}{clr}
\hline No & \multicolumn{1}{c}{ Keterangan } & \multicolumn{1}{c}{ Hasil } \\
\hline 1 & Volume Rata-Rata/Ha $\left(\mathrm{m}^{3} / \mathrm{ha}\right)$ & 253,06 \\
2 & Simpangan Baku $\left(\mathrm{m}^{3} / \mathrm{ha}\right)$ & 29,6 \\
3 & Galat Baku $\left(\mathrm{m}^{3} / \mathrm{ha}\right)$ & 4,7 \\
4 & Sampling Erorr $(\%)$ & 12,3 \\
\hline
\end{tabular}

Sumber : Data Primer Setelah di Olah, 2019.

Hasil inventarisasi jabon merah menghasilkan volume rata-rata per hektar, simpangan baku, galat baku, dan kesalahan pengambilan contoh di Kecamatan Bua (Tabel 1), didapatkanvolume rata-rata per hektar sebesar 253,06 $\mathrm{m}^{3} / \mathrm{ha}$, simpangan baku (standard deviation) sebesar $29,6 \mathrm{~m}^{3} / \mathrm{ha}$, galat baku (standard error) sebesar $4,7 \mathrm{~m}^{3} / \mathrm{ha}$, dan kesalahan pengambilan contoh (sampling error) sebesar $12,3 \%$. Hasil penelitian ini memiliki volume rata-rata per hektar lebih besar dibandingkan dengan penelitian Ismailet al. (2016). Kecamatan Majalengka memiliki volume rata-rata per hektar sebesar 92,03 $\mathrm{m}^{3} /$ ha, dengan jumlah pohon sebesar 300 pohon. Hal ini dipengaruhi oleh banyaknya tegakan jabon merah di Kecamatan Bua yang didapatkan sebesar 2.034 pohon, sehingga menghasilkan volume rata-rata sebesar 253,06 $\mathrm{m}^{3} /$ ha. Hasil inventarisasi tegakan jabon 
merah didapatkan potensi setiap desa di Kecamatan Bua seperti gambar2.

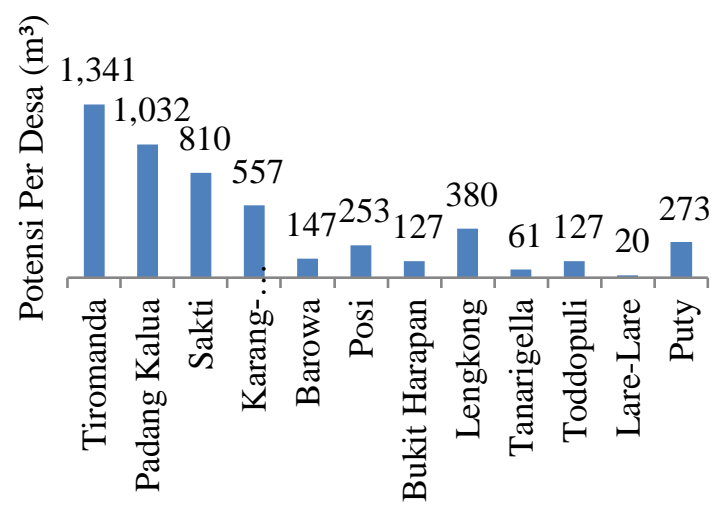

Gambar 2. Merupakan Potensi jabon merah di setiap desa yang ada di Kecamatan Bua, yang di hasilkan dari volume per hektar dikalikan dengan luas areal tegakan jabon merah di setiap desanya. Potensi jabon merah di Kecamatan Bua sebesar $5.127 \mathrm{~m}^{3}$, lebih rendah dibandingkan dengan penelitian Ismail et al. (2016), Kecamatan Majalengka memiliki potensi jabon merah sebesar $13.994 \mathrm{~m}^{3}$, hal ini dipengaruhi oleh diameter tegakan yang didapatkan lebih besar berkisaran antara 10 $\mathrm{cm}-49 \mathrm{~cm}$. Kecamatan Bua memiliki diameter tegakan yang didapatkan lebih kecil berkisaran $5 \mathrm{~cm}-39,99 \mathrm{~cm}$.

\section{Sebaran Potensi Jabon Merah}

Pemetaan sebaran merupakan proses langkah awal dalam pembuatan peta, dengan menggambarkan penyebaran kondisi sebaran secara meruang, memindahkan keadaan sesungguhnya kedalam peta dasar, yang dinyatakan dengan penggunaan skala peta (Juhadi et al. 2001). Tegakan Jabon merah di Kecamatan Bua tersebar di 12 desa, yaitu Desa Tiromanda, Desa Padang Kalua, Desa Posi, Desa Sakti, Desa Barowa, Desa Puty, Desa Tanarigella, Desa Karang-Karangan, Desa Lengkong, Desa Bukit Harapan, Desa Toddopuli, dan Desa Lare-Lare (Gambar 3).

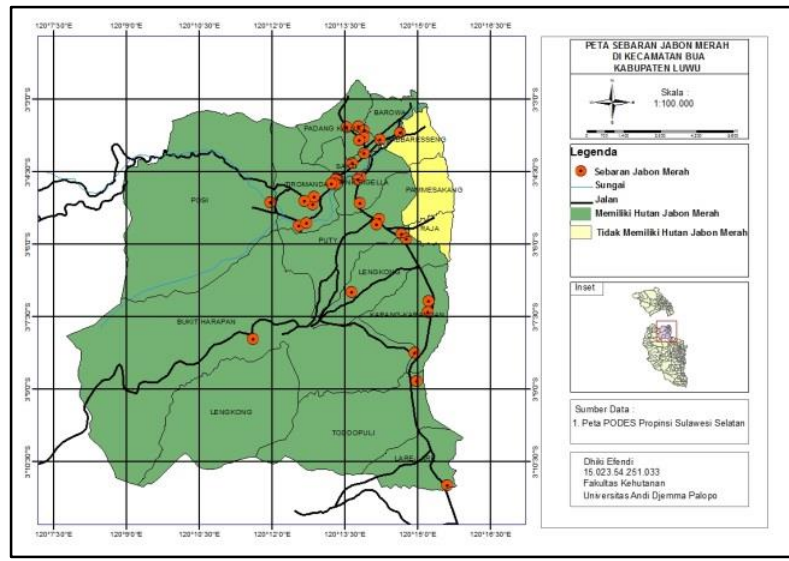

Gambar 3. Peta Sebaran Jabon Merah di Kecamatan Bua.

Berdasarkan Gambar 3, terlihat bahwa hutan rakyat jabon merah banyak tersebar di Desa Tiromanda dengan jumlah hutan rakyat jabon merah sebanyak 11 areal tegakan Jabon merah, keberadaan hutan rakyat jabon merah di Desa Tiromanda juga didukung oleh fasilitas sarana berupa : industri kayu lapis (Pt. Saemporna Kayu), jalan, dan permukiman penduduk. Hal ini disebabkan untuk meningkatkan produksi kayu industri, dan menunjang perekonomian masyarakat.

Menurut Mando et al (2015), Kabupaten Muna memiliki hutan rakyat jati dekat dengan jalan dan permukiman penduduk, hal ini dilaksanakan dalam rangka untuk meningkatkan produksi kayu industri, hutan rakyat, dan perekonomian masyarakat. Luas areal tegakan jabon merah di Kecamatan Bua terbagi di 12 desa, yaitu Desa Tiromanda, Desa Padang Kalua, Desa Posi, Desa Sakti, Desa Barowa, Desa Puty, Desa Tanarigella, Desa Karang-Karangan, Desa Lengkong, Desa Bukit Harapan, Desa Toddopuli, dan Desa Lare-Lare (Gambar 4). 


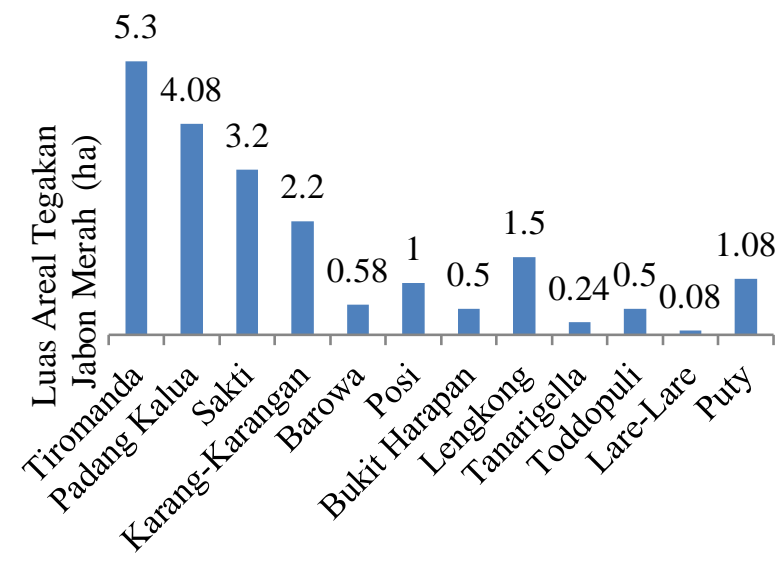

Gambar 4.Luas Areal Tegakan Jabon Merah Masing-Masing Desa di Kecamatan Bua.

Gambar 4. Merupakan luas areal tegakan Jabon merah masing-masing desa di Kecamatan Bua. Hasil identifikasi dan inventarisasi di Kecamatan Bua, Desa Tiromanda termasuk desa terluas areal tegakan jabon merah sebesar 5,3 ha, sedangkan Desa Lare-Lare desa terkecil areal tegakan jabon merah sebesar 0,8 ha. Hal ini disebabkan masyarakat Desa Tiromanda lebih banyak mengelolah hutan rakyatnya untuk sektor kehutanan, Desa Tiromanda memiliki kelompok tani hutan yang aktif dan berperan penting dalam pengelolaan hutan rakyatnya. Sedangkan masyarakat Desa Lare-Lare lebih banyak mengelolah lahannya untuk sektor pertanian dan perkebunan.

\section{KESIMPULAN DAN SARAN}

Potensi Jabon merah di Kecamatan Bua sebesar $5.127 \mathrm{~m}^{3}$ dengan volume rata-rata per ha sebesar 253,06 $\mathrm{m}^{3} /$ ha. Volume Jabon merah untuk setiap kelas diameter diperoleh sebesar $0,99 \mathrm{~m}^{3}$ untuk kelas diameter $5-10,99 \mathrm{~cm}$, $277,60 \mathrm{~m}^{3}$ untuk kelas diameter 11-19,99 cm, $338,20 \mathrm{~m}^{3}$ untuk kelas diameter 20-29,99 cm, dan $122,15 \mathrm{~m}^{3}$ untuk kelas diameter 30-39,99 cm. Sebaran Jabon merah di Kecamatan Bua, sebaran tertinggi dan terluas terletak di Desa Tiromanda sebanyak 11 areal tegakan Jabon merah dengan luasan sebesar 5,3 ha, sebaran terendah dan terkecil terletak di Desa LareLare hanya 1 areal tegakan Jabon merah dengan luasan sebesar 0,8 ha. Kecamatan Bua membutuhkan bantuan pemerintah secara intensif dalam membangun hutan rakyat, penyuluhan tentang kehutanan, dan penelitian lebih lanjut pada tegakan jabon merah yang ada di Kecamatan Bua.

\section{DAFTAR PUSTAKA}

Awang S.A., Wiyono SB, Sandiyo S . 2007. Unit Manajemen Hutan Rakyat: Proses Kontruksi Pengetahuan Lokal. Yogyakarta. Banyumili Art Network, PKHR Fahutan UGM.

Bukhari, 2015. Analisis Vegetasi Hutan Rakyat di Desa Posi Kecamatan Bua Kabupaten Luwu. Fakultas Kehutanan. Universitas Andi Djemma.Palopo.

Cahyono, T.D., S. Ohorella, dan F. Febrianto. 2012.Beberapa Sifat Kimia dan KeawetanAlami Kayu Samama (Antocephalus macrophylus Roxb.) terhadap Rayap Tanah. Jurnal Ilmu dan Teknologi Kayu Tropis Vol. 10, No. 2.

Eventi, T. 2010. Pemanfaatan SIG dalam Pemetaan Penyebaran Potensi Hutan Berbasis IHMB di IUPHHK-HA PT. Intracawood Manufacturing Kalimantan Timur. Fakultas Kehutanan. Institut Pertanian Bogor. Bogor.

Ismail, Hendrayana, dan Saputra, 2016. Inventarisasi dan Identifikasi Sebaran Jabon Merah (Anthocephalus marcophyllus) Di Hutan Rakyat Kecamatan Majalengka. Fakultas Kehutanan. Universitas Kuningan. 
Juhadi, dan Liesnoor. 2001. Desain dan Komposisi Peta Tematik. Semarang:Cv.Indoprint.

Malamassam. 2009. hutan.Universitas Inventarisasi Hasanuddin. September 2009.

Mando dan Purwanto. 2015. Sebaran Potensi Hutan Rakyat Jati Dalam Perencanaan Pembangunan Wilayah Kabupaten Muna. Fakultas Kehutanan. Universitas Halu Oleo. Kendari.

Martawidjaya A, Kartasujana, Kadir K, dan Prawira SA. 2005. Atlas Кауи Indonesia. Jilid II. Bogor: Badan Litbang Kehutanan, Departemen Kehutanan.

Safitri, E. 2009. Identifikasi dalam Inventarisasi Pengelolaan Hutan Rakyat. Departemen Kehutanan Fakultas Pertanian Universitas Sumatera Utara. Medan.

Sugiyono. 2010. Metode Penelitian Pendidikan Pendektan Kuantitatif, Kualitatif dan R\&D. bandung: Alfabeta.

Simon. 2007. Pengenalan dan Pengukuran Karateritik Pohon. UGM Press. Yogyakarta.

Tarigan, B I. S. 2009.Dimensi Serat Sludge Primer Industri Pulp Dan Kertas. Teknologi Hasil Hutan. Universitas Simatera Utara. Medan.

Widayanti, W.T dan Riyanto, S. 2005 Kajian Potensi Hutan Rakyat dan Analisis Interaksi Masyarakat dengan Sumberdaya Alam Di Kabupaten Boyolali. Jurnal Hutan Rakyat Volume VII No. 2 Tahun 2005. Yogyakarta. Fakultas Kehutanan UGM.

Wardhani, I. Y. 2011. Sifat Fisika dan Mekanika Kayu Repeh (Mangifera gedebe Miq.). Jurnal Tengkawang. Vol. 1, No. 2.
Warman, R, D. 2014. Global Wood Production From Nature Forest Peaked. Biodiversity and Conservation. Vol. 23, No. 5:63-78. 